\title{
EL COMIENZO DE LA VIDA ES SUEÑO Y LA SOLEDAD PRIMERA DE GÓNGORA
}

Fausta Antonucci

Dipartimento di Lingue, Letterature e Culture Straniere

Università Roma Tre via Valco di San Paolo, 19

00141 Roma. Italia fausta.antonucci@uniroma3.it

[Anuario calderoniano (ISSN: 1888-8046), 7, 2014, pp. 33-51]

1. El comienzo de La vida es sueño es, quizás, uno de los pasajes más estudiados y citados del teatro áureo: sobre todo por el famoso apóstrofe de Rosaura al caballo desbocado que la ha dejado a pie, sin montura, en un sitio inhóspito y salvaje. También el descubrimiento por ella y por Clarín de la cárcel de Segismundo ha recibido una gran atención crítica, por el simbolismo del espacio oscuro de la celda, apenas iluminada por una vela, en la que un hombre en cadenas y vestido de pieles como un salvaje se aparece a los dos viajeros, así como a los espectadores, quejándose por la injusticia de su destino. Entre estos dos vértices, se encuentran unos cincuenta versos que suelen despertar mucho menos interés. Lo que me propongo en estas páginas es, en cambio, analizar la secuencia inicial de La vida es sueño (vv. 1102) en su conjunto, partiendo de una constatación elemental: su uni- 
dad métrica, dada por las silvas. Además de la forma métrica y de su posición en el texto, consideraré el espacio dramático al que aluden $\mathrm{y}$ en el que se pronuncian los versos, las acciones que dramatizan, el estilo ${ }^{1}$.

Por de pronto, me parece importante subrayar la elección calderoniana de empezar La vida es sueño en silvas: de entre las obras publicadas en la Primera parte de comedias (1636) empiezan en silvas, además de La vida es sueño, La gran Cenobia (1625), El purgatorio de San Patricio (fechable entre finales de 1627 y comienzos de 1628), La puente de Mantible (antes de 1630)2. Obras, todas, de tono serio cuando no francamente trágico; con lo que podemos empezar a suponer que la apertura en silvas constituye algo parecido a una marca de género ${ }^{3}$. No contradice esta hipótesis la nómina de obras reunidas en la Segunda parte (1637) que empiezan en silvas: El mayor encanto amor, Argenis $y$ Poliarco, El mayor monstruo del mundo, A secreto agravio secreta venganza. Observemos ahora los espacios y la situación dramatizados en estas secuencias iniciales. Salta a la vista la solidaridad entre La gran Cenobia y El purgatorio de San Patricio, las dos piezas más tempranas, que se abren con la aparición en escena de un personaje "vestido de pieles» que acaba de despertarse de un sueño agorero y perturbador en un espacio dramático natural y salvaje: «desiertos horizontes», "peñas» en La gran Cenobia; un espacio marcado por la cercanía del mar y de los montes en El purgatorio de San Patricio. De momento retenemos sin duda la solidaridad de estas dos piezas tempranas con la secuencia de apertura de La vida es sueño, en lo relativo al espacio natural montuoso en el que se encuentran Rosaura y Clarín, y en lo relativo al vestido

${ }^{1}$ Este trabajo reelabora la comunicación que presenté en el Segundo Coloquio Calderoniano "Calderón palabra por palabra, verso por verso» (Universidad de Viena, 14-15 de junio de 2013), organizado por el profesor Wolfram Aichinger en el marco del proyecto de investigación titulado Secrets and Secrecy in Calderón's Comedies and in Spanish Golden Age Culture. Including a Critical Edition of "El secreto a voces» y financiado por el Austrian Science Fund FWF (Project number P 24903-G23) y el Austrian National Bank (OeNB) Jubiläumsfonds (Project number 14725).

${ }^{2}$ Las hipótesis de datación son las que refiere Iglesias Feijoo (ed.), 2006.

${ }^{3}$ Fernández Guillermo, 2008, estudia la amplia presencia de la silva en la producción dramática de Calderón, pero conectándola más bien con el tipo de situación dramática para la que se utiliza, sin examinar su colocación en relación con la estructura de la pieza (comienzo, final, sus relaciones con los cuadros, etc.). 
de pieles con el que aparece en escena Segismundo al final de la secuencia en silvas.

Pero hay que profundizar más. La secuencia inicial de El purgatorio de San Patricio prosigue con largas descripciones ticoscópicas del mar y de su furia ${ }^{4}$, que determinan el naufragio y la llegada a las playas de Irlanda de Patricio y Ludovico ${ }^{5}$ :

LEOGARIO

CAPITÁN

LESBIA
Sal, señor, a la orilla

del mar, que la cabeza crespa humilla

al monte, que le da para más pena

en prisión de cristal cárcel de arena.

Divierta tu cuidado

este monstruo nevado,

que en sus ondas dilata

a espejos de zafir marcos de plata.

[...]

Pues ¿hay cosa a la vista más suave

que ver quebrando vidrios una nave,

siendo en su azul esfera

del viento pez y de las ondas ave,

cuando corre veloz, surca ligera

$\mathrm{y}$, de dos elementos amparada,

vuela en las ondas y en los vientos nada,

aunque agora no fuera

su vista a nuestros ojos lisonjera,

porque el mar alterado,

en piélagos de montes levantado,

riza la altiva frente

y sañudo Neptuno

parece que importuno

turbó la faz y sacudió el tridente?

Tormenta el marinero se presuma,

que se atreven al cielo

montes de sal, pirámides de yelo,

torres de nieve, alcázares de espuma.

$[\ldots]$

${ }^{4}$ El término «ticoscopia» indica el «relato de acciones que se desarrollan fuera del escenario material», para utilizar las palabras de Arellano, 2001, p. 80.

${ }^{5}$ Cito de Iglesias Feijoo (ed.), 2006, pp. 215-217. 
REY

¿Qué es eso?

CAPITÁN

A nado

un hombre se ha escapado

de la cruel tormenta.

LESBIA

Y con sus brazos dar la vida intenta

a otro infelice, cuando

estaba con la muerte agonizando.

Polonia Mísero peregrino,

a quien el hado trujo y el destino

a tan remota parte,

norte vocal, mi voz podrá guiarte

si me escuchas, pues solo

por animarte hablo:

llegad.

Asimismo, un naufragio y la azarosa llegada a tierra de algunos personajes son el núcleo dramático de la secuencia inicial en silvas de una pieza más tardía como El mayor encanto amor, publicada en la Segunda parte $(1637)^{6}$ :

ULISES Saluda el peregrino

que en salado cristal abrió camino

la tierra donde llega,

cuando inconstante y náufrago se niega

del mar a la inconstancia procelosa.

Antistes

¡Salve y salve otra vez, madre piadosa!

Arquelao

Con rendidos despojos

los labios te apellidan y los ojos.

[...]

Arquelao Solo se ve de arroyos mil sulcado, cuyo turbio cristal desentonado parece, a lo que creo, desperdiciado aborto del Leteo.

Lebrel Que habemos dado temo en otro mayor mal que Polifemo.

${ }^{6}$ Cito de Fernández Mosquera (ed.), 2007, pp. 12-13 y p. 109. 
$\begin{array}{ll}\text { Floro } & \text { Quejas son lastimosas y severas } \\ \text { cuantas se escuchan de robustas fieras. } & \text { Timantes } \\ \text { Mi las copas rústicas miramos } \\ \text { destos funestos ramos, } \\ \text { no pájaros suaves } \\ \text { vemos, nocturnas sí, agoreras aves. }\end{array}$

Las palabras iniciales de Ulises, así como la situación de naufragio, se repiten casi literalmente al comienzo de Argenis y Poliarco, también publicada en la Segunda parte ${ }^{7}$.

Arcombroto
Salude el peregrino
que en salado cristal abrió camino
la tierra donde llega,
cuando inconstante y náufrago se niega
del mar a la inclemencia procelosa.
¡Salve y salve otra vez, madre piadosa!
En rendidos despojos
los labios te apelliden y los ojos.

Es evidente en todos los pasajes citados la recurrencia (subrayada con negritas) de palabras, sintagmas, artificios compositivos y figuras típicamente gongorinas en las descripciones del mar y del naufragio, así como - en El mayor encanto amor- en la descripción de la tierra a la que los náufragos han $\operatorname{arribado}^{8}$. Mientras en esta se escuchan ecos

7 Cito de Fernández Mosquera (ed.), 2007, p. 109.

8 Palabras como "peregrino» (Soledades, v. 19 y passim), "cristal» (con la significación metafórica de 'agua marina' o de 'río', Soledades, vv. 205, 244, 426, 578, 703, 836; Polifemo, vv. 192, 404, 496), "zafir» (Soledades, vv. 6, 313, 711, "zafiro», aunque nunca para metaforizar el mar; sí en cambio en Polifemo, v. 419), "pirámide» (Polifemo, v. 492), «aborto» («abortaron», Soledades, v. 262; «abortada», Polifemo, v. 74); «procelosa» («proceloso», Polifemo, v. 59), «inconstante» (Soledades, v. 404); sintagmas como «nocturnas aves» (Polifemo, v. 39), «mísero peregrino» (que conjuga el «inconsiderado peregrino» y el «mísero extranjero» de Soledades, vv. 19 y 46 respectivamente), «piélagos de montes" (Soledades, v. 44); artificios compositivos como el grupo correlativo no... sí y las bimembraciones paralelísticas; figuras como hipálages ("del viento pez y de las ondas ave»; "vuela en las ondas y en los vientos nada»), metáforas ("quebrando vidrios», "salado cristal», «montes de sal, pirámides de yelo, / torres de nieve, alcázares de espuma», «norte vocal»); conceptos o metáforas complejas (el mar «humilla» la «cabeza crespa» [cual un sujeto humano vencido; lo crespo de la espuma se asemeja a lo cres- 
de la apertura de la Fábula de Polifemo y Galatea (el nombre del cíclope lo menciona explícitamente el gracioso), en las descripciones del mar y del naufragio se escuchan más bien ecos del comienzo de la Soledad primera; ecos que refuerza la utilización repetida de la palabra "peregrino" para referirse a los náufragos. Pero, más allá de la repetición de palabras o imágenes o figuras, es la misma situación inicial de estas comedias la que manifiesta la intención calderoniana de recordar el poema gongorino; poema que - como las comedias mencionadas - se abre con el naufragio de un joven peregrino y su llegada a una playa cercada de riscos.

2. Volvamos a leer ahora la secuencia en silvas que abre La vida es sueño tratando de dejar de lado las incrustaciones de las críticas previas y atentos solo al espacio dramático que las palabras de Rosaura dibujan: un "confuso laberinto /de [...] desnudas peñas" (vv. 6-7) que es donde se ha despeñado el caballo; la "cabeza enmarañada /deste monte eminente /que abrasa al sol el ceño de la frente» (vv. 14-16) que es el punto desde el cual Rosaura se propone bajar. Luego se refiere a las «arenas» de Polonia, donde se ha escrito con sangre su llegada (vv. 18-19); se trata de un pasaje que casi ningún editor comenta, a pesar de lo extraño y en cierto sentido impropio de esta alusión a las playas de Polonia (si entendemos «arenas» como sinécdoque por «playas») ${ }^{9}$ ¿ QQué tiene que ver esta alusión en un contexto montuoso,

po del pelo] «al monte, que le da para más pena» [como el poderoso al que se le asemeja en la metáfora] «en prisión de cristal cárcel de arena» [metáfora de las ensenadas en las que se remansa lo agitado del mar, que están compuestas de agua $=$ cristal y de tierra=arena]); el mar es «monstruo nevado» (por la espuma que corona sus olas altísimas) «que en sus ondas dilata / a espejos de zafir» (los remansos del agua) «marcos de plata» (los círculos de espuma que los circundan). De estos artificios el que quizás se conozca hoy menos es la hipálage, es decir, el trastrocamiento de los adjetivos o verbos «asignados a dos sustantivos sintáctica y semánticamente relacionados en un mismo enunciado» (Mayoral, 1994, pp. 247-248). Para un útil repaso de las peculiaridades estilísticas gongorinas remito a Jammes (ed.), 1994; Ponce Cárdenas, 2001; Ponce Cárdenas (ed.), 2010. Las citas de Soledades y Polifemo remiten a Jammes (ed.), 1994 y Ponce Cárdenas (ed.), 2010, respectivamente. Más ecos gongorinos señala Gates, 1937, p. 245, en la tercera jornada de El mayor encanto amor.

${ }^{9}$ El único crítico que pone en relación el vocablo «arenas» del v. 19 con el mar, que yo sepa, es Marc Vitse, que ve en esta alusión a las playas de Polonia una manera de construir un espacio dramático insular, cerrado («Or il apparait que la mer est 
que es donde Rosaura suponemos que se ha herido (de ahí la mención de la sangre) al caer del caballo? En la anotación de mi edición de La vida es sueño propuse esta explicación: «El término arenas es una metonimia por 'tierras', que remite asimismo al significado de 'terreno acotado que se utiliza para una batalla, un torneo o una lid' (de hecho, Rosaura viaja a Polonia dispuesta a luchar para recuperar su honor) ${ }^{10}$. Ahora ya no volvería a escribir la nota de esta forma. Creo que, al escribir «arenas», Calderón quería evocar conscientemente un escenario marino cercano y opuesto al de los montes donde se ambienta la escena inicial, tal como sucede en El purgatorio de San Patricio.

La razón de esta alusión por cierto no tiene nada que ver con la realidad geográfico-política de la Polonia de entonces, por más que tantos críticos se hayan roto la cabeza para dilucidar el porqué de la presencia del mar debajo de las ventanas del palacio real, que es desde donde Segismundo arroja al impertinente Criado 2 en la segunda jornada. La razón de esta alusión hay que buscarla más bien en el influjo poderoso que ejerce en Calderón el poema gongorino de las Soledades, y que ya hemos podido comprobar en el caso de la ticoscopia del mar y del naufragio en la secuencia inicial de El Purgatorio de San Patricio. Es más: toda la secuencia en silvas que abre La vida es sueño se modela sobre la secuencia inicial de la Soledad primera, que poetiza la llegada del peregrino náufrago a una playa inhóspita, su escalada del monte que la cerca y su posterior descenso, en el crepúsculo, hasta vislumbrar de lejos la luz de una cabaña que podrá acogerle para la noche ${ }^{11}$. Voy a reproducir a continuación solo una parte de esta secuencia inicial, la que mejor nos sirve para una comparación con La vida es sueño:

présente d'un bout à l'autre du poème dramatique. De cette présence, qu'on définirait plus justement comme une absence allusive, la fonction est de désigner la clôture du lieu où se déroule le procès tragique»; Vitse, 1980, p. 8).

${ }^{10}$ Antonucci (ed.), 2008, p. 112 n. 19. Una explicación análoga es la que ofrece Rodríguez Cáceres (ed.), 2001.

11 Rivers, 1983, pp. 275-276 vio claramente la referencia gongorina en un interesante trabajo que solo aborda de forma tangencial este eco intertextual. Merece la pena citar sus palabras: «The opening scene of La vida es sueño depends heavily upon Góngora's major poems for its literary allusions. The setting itself, with its "monte fragoso" and prison-tower at twilight and the arrival of lost wanderers from another land as the violent opening action, remind us simultaneously of the shipwrecked tra- 
Besa la arena, y de la rota nave aquella parte poca

que lo expuso en la playa dio a la roca: que aun se dejan las peñas lisonjear de agradecidas señas. [...]

No bien pues de su luz los horizontes, que hacían desigual, confusamente montes de agua y piélagos de montes, desdorados los siente, cuando, entregado el mísero extranjero en lo que ya del mar redimió fiero, entre espinas crepúsculos pisando, riscos que aun igualara mal volando veloz, intrépida ala, menos cansado que confuso, escala. Vencida al fin la cumbre, del mar siempre sonante, de la muda campaña árbitro igual e inexpugnable muro, con pie ya más seguro declina al vacilante breve esplendor de mal distinta lumbre, farol de una cabaña que sobre el ferro está en aquel incierto golfo de sombras anunciando el puerto.

(vv. 29-61)

La mención de las «arenas», pues, sirve en mi opinión para poner en relación la situación de Rosaura, recién llegada a un país para ella desconocido y a un lugar inhóspito en el que ha perdido su único medio de locomoción (en su caso, el caballo), con la situación del peregrino náufrago de Góngora: ambos con problemas amorosos, «des-

veler on the steep coast at the beginning of the Soledades and of the cave of that subhuman monster Polifemus. Even the combination of heptasyllables and endecasyllables seems to be an allusion to the silvas of the Soledades [...]”. Agradezco a Wolfram Aichinger el haberme señalado la existencia de este artículo, que — debido a su título un tanto genérico- había escapado a mi repaso crítico sobre La vida es sueño. 
deñados sobre ausentes» si se me permite citar el texto gongorino modificándolo; ambos retratados en el momento en que empiezan un recorrido que los llevará al encuentro con mundos desconocidos.

Con esto no quiero por supuesto restarle importancia al motivo de la caída del caballo y a su repetición en el teatro calderoniano, muy bien observada por tantos estudiosos y reseñada con diligencia en su dramaturgia por Germán Vega ${ }^{12}$. No quiero tampoco negar que el caballo desbocado pueda ser un símbolo del desenfreno de los instintos o del riesgo en que incurren los soberbios y que como tal proyecte su luz sobre la historia de Segismundo ${ }^{13}$. Solo sugiero que se observe también toda la secuencia en su conjunto, en relación con la forma métrica escogida por Calderón que es una clara remisión a la silva gongorina ${ }^{14}$, y que refuerza los puntos de contacto con la situación inicial de la Soledad primera a los que ya me he referido. Por otra parte, el tan criticado epíteto inicial con el que Rosaura se dirige a su caballo, «Hipogrifo violento», es ya una declaración de adhesión estilística a Góngora que contiene un desafio implícito a sus detractores, y quizás sobre todo, entre ellos, a Lope. Recordemos que en el Arte nuevo de hacer comedias en este tiempo Lope había recomendado que, «si [el dramaturgo] ha de imitar a los que hablan, / no ha de ser por Pancayas, por Metauros, / hipogrifos, semones y centauros» (vv. 266268). Si es cierto que cuando Lope escribió estos versos no podía todavía estar apuntando a Góngora (la Soledad primera es de 1613 y el Arte Nuevo se escribe entre finales de 1607 y comienzos de 1608), cuando Calderón compone La vida es sueño ya son archiconocidas las

${ }^{12}$ Vega García-Luengos, 2003. En este trabajo, Germán Vega se centra en la intratextualidad calderoniana del comienzo de La vida es sueño, esbozando entre otras cosas una interesante hipótesis de autoría de El mejor padre de pobres asentada en el enorme parecido entre la apóstrofe al caballo de Rosaura y la análoga de San Juan de Dios en apertura de la comedia apenas mencionada.

${ }^{13}$ Ver por ejemplo la lectura de Valbuena, 1962.

${ }^{14}$ Aunque hay que decir que el pasaje inicial de La vida es sueño es una silva de pareados 7+11 (con una sola excepción en los vv. 49-50, que son dos endecasílabos) mientras que las silvas de las Soledades presentan una disposición más libre de rimas y de versos. Ver al respecto Jammes (ed.), 1994, pp. 143-157, y en general sobre la silva López Bueno (ed.), 1991. Rivers, 1983, p. 275 supone que la utilización por Calderón de los pareados «can be explained as a concession to the mnemonic demands of the actors, who may well have declined to cope with a complexity of rhyme scheme comparable to that of the first ten lines of the Soledad primera». 
críticas de Lope a la poesía culta y por lo tanto es muy posible que a Calderón se le ocurriera remitir de forma solapada y con intenciones polémicas a un texto de Lope, aunque este fuera anterior al inicio de la disputa sobre el gongorismo ${ }^{15}$.

3. Pero volvamos al trayecto que recorre Rosaura en la secuencia en silvas que estamos analizando, como el peregrino de las Soledades pero en compañía de un criado gracioso, como conviene a un personaje de teatro. En lugar de una luz lejana, como en la Soledad primera, lo que Rosaura y Clarín divisan por de pronto es un «edificio", «tan breve» que parece "peñasco que ha rodado de la cumbre»; tras solo cinco versos están más cerca (se trata de un ejemplo típico de lo que Javier Rubiera llama el «espacio itinerante») ${ }^{16}$ y descubren que el edificio tiene la puerta abierta. Dice Rosaura: «La puerta /-mejor diré funesta boca- abierta / está, y desde su centro / nace la noche, pues la engendra dentro». La forma de pintar la oscuridad total del interior del edificio recuerda obviamente el pasaje famoso de la Fábula de Polifemo y Galatea que describe la cueva del cíclope: donde ya la apertura se metaforizaba como «boca» (v. 32) y la negrura de su interior era "caliginoso lecho [...] de la negra Noche» (vv. 37-38) ${ }^{17}$. Por otra parte, este eco del Polifemo gongorino no es el primero que resuena en La vida es sueño: cuando Rosaura había dicho que divisaba a lo lejos el edificio «a la medrosa luz que aún tiene el día» (v. 52), el espectador culto podía haber recordado el endecasílabo de la Fábula de Polifemo y Galatea "pisando la dudosa luz del día» (v. 72).

Rosaura y Clarín se acercan aún más y empiezan a escuchar ruido de cadenas y quejidos de un ser humano; Rosaura discierne algo,

15 «a raíz del dictamen de Lope de Vega, "hipogrifo" era considerado en el lenguaje del teatro un "vocablo exquisito", un cultismo a evitar, por lo que podemos suponer que Calderón, al colocarlo en un lugar tan privilegiado como el inicio de la comedia, debió de ser plenamente consciente del carácter transgresor que la adopción de dicha voz conllevaba» (Güntert, 2002, p. 495, con una nota que recuerda a otros críticos que también han comentado el aspecto metapoético de la utilización del término «hipogrifo»).

16 Rubiera, 2005, pp. 107 y ss.

${ }^{17}$ Ya lo observaba Samonà, 1967, p. 72. Falta este pasaje, así como todo el comienzo de La vida es sueño, en el recuento de pasajes gongorinos en Calderón que hace Gates, 1937. 
«aunque de lejos», y pregunta: «¿No es breve luz aquella / caduca exhalación, pálida estrella, / que en trémulos desmayos, /pulsando ardores y latiendo rayos, / hace más tenebrosa / la obscura habitación con luz dudosa?» (vv. 85-90). Más de un crítico ha interpretado la vela vacilante que acompaña al desesperado Segismundo como un símbolo del alma, cuya luz todavía no ha abandonado al hombre recluido en la cárcel del cuerpo y de los instintos; o como un símbolo de la sindéresis o scintilla conscientiae ${ }^{18}$. Aun teniendo en cuenta la posibilidad de una interpretación simbólica, creo que hay que reconocer ante todo que la situación descrita por Rosaura presenta una vez más ecos gongorinos: una luz incierta que rompe la oscuridad (antítesis esta muy barroca), tal como el «breve esplendor de mal distinta lumbre» surge a lo lejos en el «golfo de sombras» que rodea al peregrino de la Soledad primera $^{19}$.

Sin embargo, a diferencia de lo que le sucede al peregrino, para Rosaura y Clarín no hay ninguna cálida acogida al final de su trayecto. En vez de amparo y comida, encuentran angustia, desamparo, agresividad, y finalmente son apresados y condenados a muerte. Explicar estas diferencias requiere considerar de forma más detenida el espacio dramático al que llegan la dama disfrazada y su criado. Como ya se ha dicho, la cárcel de Segismundo se presenta al espectador con los rasgos de un elemento natural: se parece a un peñasco, y se describe con características análogas a las de la cueva del cíclope en la Fábula de Polifemo y Galatea. No es la primera vez que Calderón incluye una cueva entre los espacios dramáticos de una comedia suya: me refiero a la larga descripción de la caverna mágica que se encuentra al final de la segunda jornada de El Purgatorio de San Patricio ${ }^{20}$. Como en La

18 Entre ellos, recuerdo especialmente Samonà, 1967, pp. 101-102 y Delgado, 2002, respectivamente.

19 «Her [Rosaura's] discovery of a flickering light contains allusions to the peregrino's discovery of the cabreros at the beginning of the first Soledad" (Rivers, 1983, p. 257).

20 «Huyendo de mí misma he penetrado / deste rústico monte la espesura, / cuyo ceño, de robles coronado, / amenazó del sol la lumbre pura, / por que en su oscuro centro, sepultado / mi delito, viviese más segura / hallando puerto en seno tan profundo / a los airados piélagos del mundo. / [...] /¿No ves ese peñasco que parece / que se está sustentando con trabajo / y con el ansia misma que padece / ha tantos siglos que se viene abajo? / Pues mordaza es que sella y enmudece / el aliento a una 
vida es sueño, el descubrimiento de la cavidad lo hace allí una mujer, Polonia, que buscaba allí refugio; cuenta que, al acercarse y querer entrar en la gruta, empezó a escuchar quejas, «desesperadas voces», «blasfemias, maldiciones». La situación es, pues, exactamente la misma que la de Rosaura en la secuencia de La vida es sueño que estamos comentando. En El Purgatorio de San Patricio la descripción de la cueva es muy larga, y está impregnada de ecos de la Fábula de Polifemo y Galatea $^{21}$ y aún más de lo que se detecta en La vida es sueño; intertextualidad esta que se refuerza gracias al uso de la octava real. Pero Polonia en El Purgatorio de San Patricio no es sino, por decirlo así, un centinela de la gruta; al percatarse de que se trata de un espacio mágico no se adentra en él, y vela porque nadie más entre allí.

La relación de Rosaura con la cueva-cárcel es de todo punto distinta: pasa el umbral, y cuando ha penetrado en el espacio misterioso, no le es posible ya huir, ha quedado atrapada. No en vano Clarín dice que quisiera huir «los rigores / desta encantada torre» (vv. 8283): el remite, clarísimo, es a los espacios encantados de los libros de caballerías, que pueden ser bien castillos, bien cuevas. Espacios iniciáticos, donde se pone a prueba el valor del caballero, y donde le esperan situaciones difíciles o regalos inesperados ${ }^{22}$. Rosaura encontrará ambas cosas. Situaciones dificiles son sin ninguna duda la agresión de Segismundo tras haberse dado cuenta de que Rosaura ha escuchado sus quejas, y el arresto al que la somete Clotaldo cuando descubre que ha penetrado en la torre. De ambas situaciones sabrá desempeñarse

boca, que debajo / abierta está, por donde con pereza / el monte melancólico bosteza. / Esta, pues, de cipreses rodeada, / entre los labios de una y otra peña, / descubre la cerviz desaliñada, / suelto el cabello, a quien sirvió de greña / inútil yerba, aun no del sol tocada, / donde en sombras y lejos nos enseña /un espacio, un vacío, horror del día, / funesto albergue de la noche fría. / Yo quise entrar a examinar la cueva / para mi habitación. Aquí no puedo / proseguir, que el espíritu se eleva, / desfallece la voz, crece el denuedo. / ¡Qué nuevo horror, qué admiración tan nueva / os contara, a no ser tan dueño el miedo, / helado el pecho y el aliento frío / de mi voz, de mi acción, de mi albedrío! / Apenas en la cueva entrar quería, / cuando escucho en sus cóncavos, veloces / — como de quien se queja y desconfia / de su dolor-, desesperadas voces» (Iglesias Feijoo, ed., 2006, pp. 270-271).

${ }^{21}$ Lo subraya Gates, 1937, pp. 252-253.

22 Para un estudio de estos espacios, y una antología de su presencia en los libros de caballerías, remito a Neri, 2007, pp. 97 y ss. 
con el comportamiento adecuado, mostrándose humilde y rendida ${ }^{23}$, pero al mismo tiempo aprovechando el momento oportuno para dar cuenta a Clotaldo del secreto que encierra su espada, el don mágico que le ha entregado su madre y que, de hecho, le salvará la vida. Este es el premio o regalo inesperado que encuentra Rosaura al final de esta su primera aventura: la protección de Clotaldo, que ella no sabe a qué se debe, pero gracias a la cual podrá ser admitida en palacio y acercarse a Astolfo.

Se trata, como puede verse, de una reelaboración de situaciones típicas de los libros de caballerías, adecuadas al comportamiento esperable en una mujer, por más que esté disfrazada de hombre. En el teatro de Calderón, las referencias a los libros de caballerías son continuas, a veces en plan serio, como sucede en sus comedias caballerescas, a veces en plan irónico, como sucede en algunas de sus comedias de capa y espada cuando algún criado miedoso piensa estar reviviendo las aventuras de Amadís y otros famosos caballeros ${ }^{24}$. La puesta en relación de la cárcel de Segismundo con la cueva mágica y en general con los espacios encantados de los libros de caballerías es necesaria

23 «Segismundo: Sólo porque me has oído, / entre mis membrudos brazos / te tengo de hacer pedazos. / CLARín: Yo soy sordo, y no he podido / escucharte. Rosaura: Si has nacido / humano, baste el postrarme / a tus pies para librarme» (vv. 183-189). «Rosaura:Ya que vi que la soberbia / te ofendió tanto, ignorante / fuera en no pedirte humilde / vida que a tus plantas yace. / Muévate en mí la piedad; / que será rigor notable / que no hallen favor en ti / ni soberbias ni humildades» (vv. 339-346). Sobre la importancia en La vida es sueño del «vencimiento de la soberbia por la humildad» ha escrito palabras iluminantes Egido, 2013, pp. 543 y ss.

${ }^{24}$ Un ejemplo interesante procede de la tercera jornada de La dama duende (cito de Antonucci, ed., 2005), cuando Cosme, el criado de don Manuel, se ve arrastrado por el duende (en realidad se trata de Isabel, la criada de doña Ángela) y entra en el cuarto de la dama en plena noche, exclamando: "Yo ¿soy Cosme o Amadís? /¿Soy Cosmico o Belianís?» (vv. 2608-2609). Al comienzo de la tercera jornada, una aventura análoga pero más complicada le había tocado al amo de Cosme, don Manuel: había tenido que subir a una silla de manos en plena noche y en un cementerio; tras muchísimas vueltas, lo habían dejado en un portal oscuro y desde allí una mujer lo había guiado «a escuras y por el tiento, / de aposento en aposento, /sin oír, hablar ni ver» (vv. 2270-2272) hasta que, por fin, ve luz por el resquicio de una puerta y se le aparecen Ángela y sus criadas ataviadas como grandes damas. Situación esta en la que se repite, a lo cómico, la de Rosaura y Clarín en La vida es sueño: un trayecto en las sombras, la entrada en un lugar desconocido y oscuro, una luz que aparece y revela quién habita el lugar mágico. 
para entender algunos aspectos problemáticos en la construcción del espacio dramático de la secuencia que estamos analizando. ¿Cómo es posible, por ejemplo, que Clarín y Rosaura puedan acercarse tanto a la cárcel y aun penetrar en ella, sin encontrar ningún centinela que les vede el acceso? Y ¿por qué, una vez han entrado, no pueden huir, si es que la puerta de acceso sigue abierta como la han encontrado hace poquísimo? Estas preguntas no tienen respuesta lógica: el espacio en el que penetran Rosaura y Clarín es un espacio misterioso y mágico, creado y delimitado por sus propias palabras. El paso de la maleza del monte al interior de la cárcel de Segismundo es además uno de los ejemplos más patentes de la fluidez del espacio dramático en el teatro áureo: la puerta abierta (la "funesta boca») de la que habla Rosaura no tiene consistencia real en el tablado; el movimiento de acercamiento y de ingreso que realizan Rosaura y Clarín solo se da en sus palabras y ninguna acotación señala su salida del escenario. En cambio, la celda de Segismundo sí tiene consistencia escénica, mostrándose a los espectadores cuando se abre uno de los tres nichos de la pared de fondo, probablemente el del vestuario, dejando ver a Segismundo (Descúbrese Segismundo con una cadena y la luz, vestido de pieles). La celda debe abrirse para ello precisamente, para que se vea al protagonista, y también para permitir el acercamiento de Rosaura y Clarín, sin el cual Segismundo no podría más tarde «asir» a Rosaura para ahogarla entre sus «membrudos brazos».

4. Es evidente que lo que Calderón busca en esta escena no es la lógica estricta de lo verosímil, sino la lógica poética que exige que los dos peregrinos puedan entrar libremente en la cárcel, como si fuese un lugar natural y no vigilado; y que puedan acercarse hasta el punto de ser objeto de una agresión por parte de Segismundo. Este, como apunta la acotación, aparece en el tablado vestido de pieles, es decir, con el atuendo típico del salvaje. Nada más común que la asociación entre el salvaje y la cueva, como muestra entre otras cosas la misma Fábula de Polifemo y Galatea. Nada más común que la presencia de un salvaje entre los monstruos que amenazan a los protagonistas de los libros de caballerías, recurso este entre fantástico y exótico que no deja de explotar Calderón en algunas de sus comedias caballerescas y mitológicas (Los tres mayores prodigios, El jardín de Falerina), siguiendo una línea que tiene quizá su antecedente más directo en $E l$ premio de la 
hermosura (1611-1614) de Lope de Vega. La aparición de un personaje vestido de pieles al final del trayecto de Rosaura y Clarín, tras su entrada en la cueva-cárcel, evoca pues de forma transparente una situación tópica de las aventuras caballerescas.

Por otra parte, cuando Segismundo ase a Rosaura con la intención de ahogarla, ya no puede ser confundido con el salvaje monstruoso, mudo o semimudo, de los libros de caballerías o de pastores: sus famosísimas quejas - que inauguran la secuencia en décimas sucesiva a las silvas de apertura - revelan con toda evidencia que se trata de un hombre, cuya desdicha suscita la compasión, más que el miedo, de Rosaura. Aunque, como dice repetidamente, es «un compuesto de hombre y fiera» (vv. 1547), una «fiera humana» (v. 3175), no es de ningún modo el ser sobrenatural que señala la tradición caballeresca. Al contrario, se parece muchísimo más - como he tratado de mostrar en otras ocasiones - al héroe salvaje de algunas comedias palatinas de los dramaturgos de la generación anterior, en primer lugar Lope de Vega y Guillén de Castro ${ }^{25}$.Y a partir de este momento, de hecho, los ecos del modelo épico-caballeresco dejan de escucharse en La vida es sue$\tilde{n} o$, para volver a aflorar solo en la tercera jornada: primero en las octavas que relatan los desastres de la guerra vistos desde el bando de Basilio y sus sostenedores (vv. 2428-2491) ${ }^{26}$, después en el cuadro sucesivo y último, que empieza, de forma paralela al comienzo de la pie$\mathrm{za}$, en silvas.

Este cuadro se abre con la entrada en escena de Segismundo (v. $2655+)$ al frente de su ejército, profiriendo palabras en las que se manifiesta la conciencia del propio valor; poco después, aparece en el tablado Rosaura (v. 2689+), con espada y daga, y tras un completo relato de su historia le ofrece a Segismundo su ayuda para derrotar al bando de Basilio y Astolfo, «mezclando, / entre las galas costosas / de Dïana, los arneses / de Palas» (vv. 2886-2889). La secuencia en octavas del cuadro anterior, que he mencionado poco antes, se cerraba de forma casi paralela con las palabras belicosas de Basilio, dispuesto a «vencer valiente a un hijo ingrato» (v. 2485), y de Estrella que decla-

${ }^{25}$ Ver sobre todo Antonucci, 1995, con bibliografia que remite a importantes trabajos anteriores sobre el mismo tema, y Antonucci, 2004.

${ }^{26}$ Sobre la función de estas octavas como expresión del componente épico que puede caracterizar el modelo trágico, remito a Antonucci, 2012b. 
raba que habría «de volar sobre tendidas alas /a competir con la deidad de Palas» (vv. 2490-2491). Todo parece estar preparado, pues, para mostrar en escena el enfrentamiento entre los dos bandos, con alguna escena de sabor épico, como las que Calderón construye en piezas más tempranas cuales Judas Macabeo, El sitio de Bredá, La gran Cenobia. Nada de ello sucede, en realidad, ni en el tablado ni fuera, relatado por ticoscopia: de la guerra, solo vemos la muerte en escena de un soldado cobarde (Clarín, vv. 3071-3095) y el desconcierto de los derrotados perseguidos por los vencedores (vv. 3096-3157). El verdadero enfrentamiento, la lucha verdadera, son los que los protagonistas realizan en su foro interior, triunfando sobre algunas instancias de sí mismos y sobre el destino ${ }^{27}$ : el primer personaje que sale victorioso de esta lucha interna es, obviamente, Segismundo, primero ante Rosaura, luego ante su padre; pero también protagoniza una victoria análoga Basilio, cuando entiende la lección de la muerte de Clarín y decide enfrentarse a su hijo aceptando el riesgo que puede derivarle de esta elección.

Se trata de un giro notable que Calderón da a la disposición épica que se observa en sus piezas primerizas clasificables como dramas, cuando no como experimentos de tragedia ${ }^{28}$. En este contexto, me parece extremadamente interesante que, al comienzo de este cuadro último, las silvas tomen el relevo (sobre todo con respecto a las octavas épicas de los vv. 2428-2491) creando un efecto de eco con el comienzo de la pieza ${ }^{29}$. El teatro de la acción también parece ser el mismo que el del comienzo, puesto que más adelante - aunque ya fuera de la secuencia en silvas - se habla de «peñas» (v. 3057), de «las espesas ramas / dese monte» (v. 3127-3128), de «lo intrincado del monte» (v. 3136). Sin embargo, la torre-cárcel ha desaparecido de este espacio dramático; y, paralelamente, han cambiado los protagonistas. Por

27 Es, al menos en el caso del personaje de Segismundo, un ejemplo de ese bellum intestinum que luego Calderón explotará, con connotaciones de tipo más francamente teológico, en sus autos, mostrándonos al Hombre escindido entre Culpa y Gracia. Ver al respecto Egido, 1982, pp. 181-196.

28 Sobre las experimentaciones del joven Calderón con el modelo trágico, remito a Antonucci, 2011 y 2012a.

${ }^{29}$ En este pasaje (vv. 2656-2689) aunque se trata, como al comienzo de la pieza, de una silva de pareados, es más irregular la composición $7+11$, habiendo a menudo pareados $7+7$ y $11+11$. 
de pronto, Segismundo y Rosaura aparecen en el tablado en orden inverso con respecto a la secuencia inicial. Primero sale Segismundo, ahora libre e investido de la dignidad de general, aunque todavía con el vestido de pieles, ya no solo símbolo de la naturaleza ferina del protagonista, que está siendo paulatinamente controlada, sino de fuerza y de autoridad (como en los salvajes de Lope de Vega y Guillén de Castro). Después sale Rosaura, ya no disfrazada, desarzonada y perdida, sino a caballo y «airosa» (v. 2687).

Este quiasmo, subrayado por la vuelta de las silvas y del espacio dramático del comienzo, es figura del cambio, de la inversión de destino que están a punto de lograr ambos protagonistas. La Rosaura «náufraga» que empezaba dolorosamente su recorrido — con tantos ecos del peregrino de las Soledades - en la apertura de La vida es suenoo, está a punto de concluir felizmente su búsqueda, con el logro del objetivo que la había impulsado inicialmente a la aventura. El salvaje que Rosaura y Clarín habían descubierto en la cueva-cárcel está a punto de transformarse definitivamente en príncipe, abandonando por completo los rasgos monstruosos que heredaba su figura, a través de una larga cadena textual, de la tradición fantástica épico-caballeresca. 


\section{Bibliografía}

Antonucci, F. El salvaje en la Comedia del Siglo de Oro. Historia de un tema de Lope a Calderón, Pamplona / Toulouse, Anejos de RILCE / L.E.S.O., 1995. Ahora: Alicante, Biblioteca Virtual Miguel de Cervantes, 2005 (edición digital a partir de la de 1995). http://www.cervantesvirtual.com/FichaObra.html?Ref=12455

- "Calderón riscrittore: il caso de La vida es sueño», en Teatri del Mediterraneo. Riscritture e ricodificazione tra '500 e '600, ed. V. Nider, Trento, Editrice Università degli Studi di Trento, Dipartimento di Scienze Filologiche e Storiche, 2004, pp. 45-57.

- (ed.), P. Calderón de la Barca, La dama duende, Barcelona, Crítica (Clásicos y modernos), 2005.

- (ed.), P. Calderón de la Barca, La vida es sueño, Barcelona, Crítica (Clásicos y modernos), 2008.

— «Las emociones trágicas y el paradigma de la tragedia en el teatro del joven Calderón: unas calas», en Emocionar escribiendo. Teatralidad y géneros literarios en la España áurea, ed. L. Gentilli y R. Londero, Madrid / Frankfurt, Iberoamericana / Vervuert, 2011, pp. 129-146.

- «Algunas calas en el tratamiento del modelo trágico por el joven Calderón», Mélanges de la Casa de Velázquez. Nouvelle série, 42 (1), 2012a, pp. 145-162.

- «La octava real entre épica y tragedia en las comedias de la Primera parte de Calderón», Iberoromania, 75-76, 2012b, pp. 142-159.

Arellano, I., «Espacios dramáticos en los dramas de Calderón», en Calderón: sistema dramático y técnicas escénicas. Actas de las XXIII Jornadas de Teatro Clásico. Almagro, 11, 12 y 13 de julio de 2000, ed. F. B. Pedraza Jiménez, R. González Cañal y E. Marcello, Cuenca, Universidad de Castilla-La Mancha / Festival de Almagro, 2001, pp. 77-106.

Delgado, M., "Sindéresis, ley natural y sentido moral en La vida es sueño», en Ayer y hoy de Calderón. Actas seleccionadas del Congreso Internacional celebrado en Ottawa del 4 al 8 de octubre del 2000, ed. J. M. ${ }^{a}$ Ruano de la Haza y J. Pérez Magallón, Madrid, Castalia, 2002, pp. 107-124.

Egido, A. La fábrica de un auto sacramental: Los encantos de la Culpa, Salamanca, Universidad de Salamanca, 1982; y como: «La fábrica de un auto: Los encantos de la Culpa», en El gran teatro de Calderón. Personajes, temas, escenografía, Kassel, Reichenberger, 1995, pp. 87-196.

— "¡Ay, mísero de mí! ¡Ay, infelice!’ Apuntes sobre La vida es sueño», Bulletin of Spanish Studies: Hispanic Studies and Researches on Spain, Portugal and Latin America, 90, 2013, pp. 535-549.

Fernández Guillermo, L., «La silva: forma métrica clave en la obra dramática de Calderón», Anuario Calderoniano, 1, 2008, pp. 105-126. 
Fernández Mosquera, S. (ed.), P. Calderón de la Barca, Segunda parte de comedias, Madrid, Fundación José Antonio de Castro, 2007.

Gates, E. J., "Góngora and Calderón», Hispanic Review, 5, 1937, pp. 241-258.

Güntert, G., "La vida es sueño: algo más sobre el "hipogrifo violento"», en Calderón 2000. Homenaje a Kurt Reichenberger en su 80 cumpleaños. Actas del Congreso Internacional IV centenario del nacimiento de Calderón, Universidad de Navarra, septiembre 2000, ed. I. Arellano, Kassel, Reichenberger, 2002, pp. 495-507.

Iglesias Fejoo, L. (ed.), P. Calderón de la Barca, Primera parte de comedias, Madrid, Biblioteca Castro, 2006.

Jammes, R. (ed.), L. de Góngora, Soledades, Madrid, Castalia, 1994.

López Bueno, B. (ed.), La silva. Primer encuentro internacional sobre poesía del Siglo de Oro, Sevilla / Córdoba, Universidad de Sevilla / Universidad de Córdoba, 1991.

Mayoral, J. A., Figuras retóricas, Madrid, Síntesis, 1994.

Neri, S., Antología de las arquitecturas maravillosas en los libros de caballerías, Alcalá de Henares, Centro de Estudios Cervantinos, 2007.

Ponce Cárdenas, J., Góngora y la poesía culta del siglo XVII, Madrid, Arcadia de las Letras, 2001.

Ponce Cárdenas, J. (ed.), L. de Góngora, Fábula de Polifemo y Galatea, Madrid, Cátedra, 2010.

Rivers, E. L., "Written poetry and Oral Speech Acts in Calderón's Plays», en Aureum Saeculum Hispanum. Beiträge zu Texten des Siglo de Oro. Festschrift für Hans Flasche zum 70. Geburtstag, Wiesbaden, Steiner, 1983, pp. 271284.

Rodríguez Cáceres, M. (ed.), P. Calderón de la Barca, La vida es sueño, Barcelona, Octaedro, 2001.

Rubiera, J., La construcción del espacio en la comedia española del Siglo de Oro, Madrid, Arco Libros, 2005.

Rull, E. (ed.), P. Calderón de la Barca, La vida es sueño (comedia, auto y loa), Madrid, Alhambra, 1980.

SAmonà, C., "Saggio di un commento a La vida es sueño» (1967), ahora en id., Ippogrifo violento, Milano, Garzanti, 1990, pp. 17-108.

VAlbuena Briones, Á., «El simbolismo en el teatro de Calderón: La caída del caballo» (1962), en Calderón y la crítica: historia y antología, ed. M. Durán y R. González Echevarría, vol. II, Gredos, Madrid, 1976, pp. 694-713. Vega García-Luengos, G., «Ecos de Rosaura (para leer mejor el inicio de La vida es sueño e incrementar el repertorio calderoniano)», Criticón, 8788-89, 2003, pp. 887-898.

Vitse, M., Segismundo et Serafina, Toulouse, Institut d'Études Hispaniques et Hispano-Américaines / Université de Toulouse-Le Mirail, 1980. 